\title{
Analysis of Switching Transient Overvoltages in the Power System of Floating Production Storage and Offloading Vessel
}

\author{
Haoyan Xue and Marjan Popov
}

\begin{abstract}
Large transient overvoltages are normally caused by vacuum circuit breaker (VCB) switching operation during disconnection of induction motors. In this paper VCBs, cables, generators, busbars, induction motors and surge arresters are modeled by making use of ATP-EMTP. Switching transient overvoltages of four typical induction motors are analyzed under starting, full load and light load working conditions in a power system of a Floating Production Storage and Offloading (FPSO) vessel. A suitable protection against the switching transient overvoltage is proposed and the results are presented
\end{abstract}

Keywords: switching transient overvoltage, ATP-EMTP, FPSO, VCBs, induction motors, surge protection.

\section{INTRODUCTION}

$\mathrm{F}^{\prime}$ LOATING production storage and offloading (FPSO) vessel is a floating unit used by the offshore petroleum industry for the processing of hydrocarbons and for oil storage. The $11 \mathrm{kV}$ electrical power system of FPSO vessel is very compact. Thirteen induction motors ranging from $0.8 \mathrm{MW}$ to 10.9 MW are working together to provide power to different machines such as compressors and pumps for supplying continued process of oil and gas production. Each motor is equipped with a VCB or a fused vacuum contactor, depending on the rated motor power. During motor switching, overvoltages could take place, and when the overvoltage reaches the motor's basic insulation level (BIL), the insulation may be damaged and might fail. Consequently, the total reliability and the security of electrical power system in the FPSO vessel are decreased.

The major contribution of this work is to check the possible switching transient overvoltages that may occur for four typical induction motors, and if the overvoltage exceeds the motor's BIL, a suitable solution to mitigate the overvoltage should be proposed.

H. Xue was with the Delft University of Technology, Faculty of EEMCS, Mekelweg 4, 2628 CD Delft, The Netherlands. Currently, he is with the Yinchuan Power Supply Bureau, Xinchangdonglu 222, 750011, Ningxia, China (e-mail: Haoyanxue1987@gmail.com).

M. Popov is with the Delft University of Technology, Faculty of EEMCS, Mekelweg 4, 2628 CD Delft, The Netherlands (e-mail: M.Popov@ieee.org).

Paper submitted to the International Conference on Power Systems Transients (IPST2013) in Vancouver, Canada July 18-20, 2013.

\section{DESCRIPTION OF THE SYSTEM}

The simplified layout of $11 \mathrm{kV}$ power system is illustrated in Fig. 1. The motors are supplied with electricity from three main generators connected to the same busbar. Some induction motors and transformers, which have the rated power around 1 MW to $4 \mathrm{MW}$ are not shown in Fig. 1. The $11 \mathrm{kV}$ network is with isolated neutral point. Four typical induction motors under starting, full and light load conditions are analyzed: the 10.2 MW main gas compressor A motor (T711) connected by $180 \mathrm{~m}$ cable to a VCB; the $10.2 \mathrm{MW}$ main gas compressor B motor (T713) connected by $300 \mathrm{~m}$ cable to a VCB; the 5.5 MW water injection pump motor (T261) connected by a 160 $\mathrm{m}$ cable to a VCB; the $1.25 \mathrm{MW}$ refrigerant compressor motor (T794) connected by $240 \mathrm{~m}$ cable to a VCB.

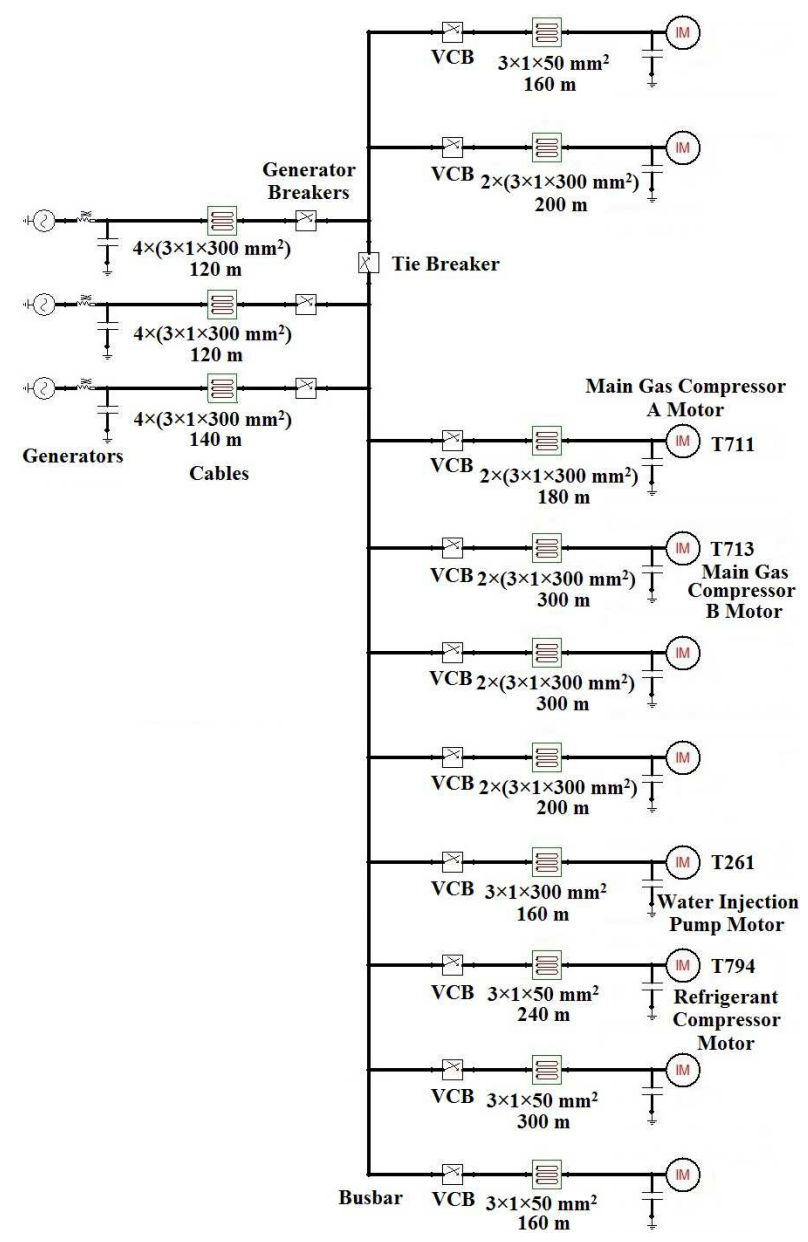

Fig. 1 Simplified layout of $11 \mathrm{kV}$ power system in FPSO Vessel. 


\section{SYSTEM MODELING}

\section{A. Vacuum Circuit Breaker Modeling}

In order to perform transient analysis in power system, a model of a VCB that takes into account multiple restrikes is very important. The VCB model requires chopping currents, dielectric recovery strength and quenching capabilities at high frequencies. The applied method of modeling is fully described in [1]-[3].

In this study, a $\mathrm{Cu} / \mathrm{Cr}(75 / 25 \%)$ contact material is assumed, which is normally used for modern VCBs. Hence, the mean value of current chopping is $5 \mathrm{~A}$ [3]. The statistical characteristics of current chopping are represented by normal distribution with mean value $5 \mathrm{~A}$ and $15 \%$ standard deviation.

The cold gap breakdown is considered in this work, the dielectric strength is according to [1] and represented by (1),

$$
U=A\left(t-t_{\text {open }}\right)+B
$$

where $U$ is the value of the dielectric strength, $A, B$ are constants and $t_{\text {open }}$ is the opening time of the contacts. The statistical characteristics of dielectric strength are represented by using normal distribution with the defined mean value and $15 \%$ standard deviation.

When a reignition occurs, the high frequency (HF) current is superimposed to the power frequency current. The HF current has several current zero crossing points and the VCB can clear the HF current in one of those current zero points. The value is the linear relationship between the changing rate of current and the time. The typical equation is shown below [1],

$$
\frac{d i}{d t}=C\left(t-t_{\text {open }}\right)+D
$$

where $d i / d t$ is the current slope, $C, D$ are constants and $t_{\text {open }}$ is the opening time of VCB. The mean value of quenching capability is calculated by (2) and the statistical value is calculated by using normal distribution with the defined mean value and $15 \%$ standard deviation. If the changing rate of $\mathrm{HF}$ current in the zero point is smaller than $d i / d t$, the HF current will be extinguished. The values of $A, B, C$ and $D$ parameters are shown in Table I.

TABLE I

DIELECTRIC PARAMETERS AND QUENCHING CAPABILITY PARAMETERS

\begin{tabular}{|ll|l|}
\hline$A$ & $(\mathrm{kV} / \mathrm{ms})$ & $20-30$ \\
\hline$B$ & $(\mathrm{~V})$ & 0 \\
\hline$C$ & $\left(\mathrm{~A} / \mu \mathrm{s}^{2}\right)$ & 0 \\
\hline$D$ & $(\mathrm{kA} / \mu \mathrm{s})$ & $0.5-0.7$ \\
\hline
\end{tabular}

A single phase test circuit of a VCB is shown in Fig. 2. The basic structure consists of a voltage source $6.35 \mathrm{kV}$, a source side inductance and a capacitance of $5 \mathrm{mH}$ and $100 \mathrm{nF}$ respectively. The cable is represented by a resistance and an inductance of $2 \Omega$ and $0.04 \mathrm{mH}$ respectively. The capacitance of the load and the cable is $10 \mathrm{nF}$. The cable ends up with an ohmic-inductive load of $10 \mathrm{k} \Omega$ and $120 \mathrm{mH}$. A damping resistance of $50 \Omega$, a capacitance of $0.2 \mathrm{nF}$ and an inductance of $0.5 \mathrm{nH}$ represent the VCB gap. The values of different elements are taken from [2].

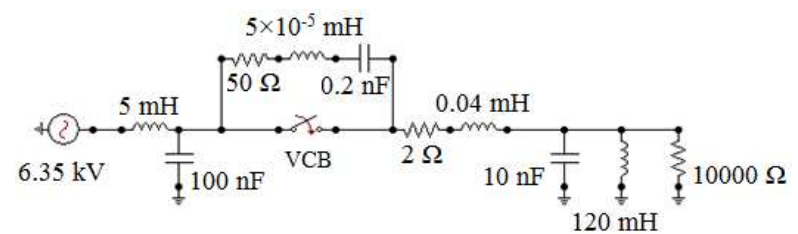

Fig. 2 Single phase test circuit of VCB.

After the contacts of the VCB are opened, the dielectric strength of the vacuum gap will increase with the time. When the increase of the transient recovery voltage (TRV) is faster than the increase of the dielectric strength, a reignition takes place. When the rate of rise of the HF current is lower than the quenching capability of the VCB in one of its zero points, the HF current is interrupted and the TRV appears again, as shown in Fig. 3. After multiple reignitions have occurred, the TRV is built to a high level, while the dielectric strength of the vacuum gap is also increased due to the contact movement. Once the dielectric strength could withstand the TRV peak, the load current will be successfully interrupted.

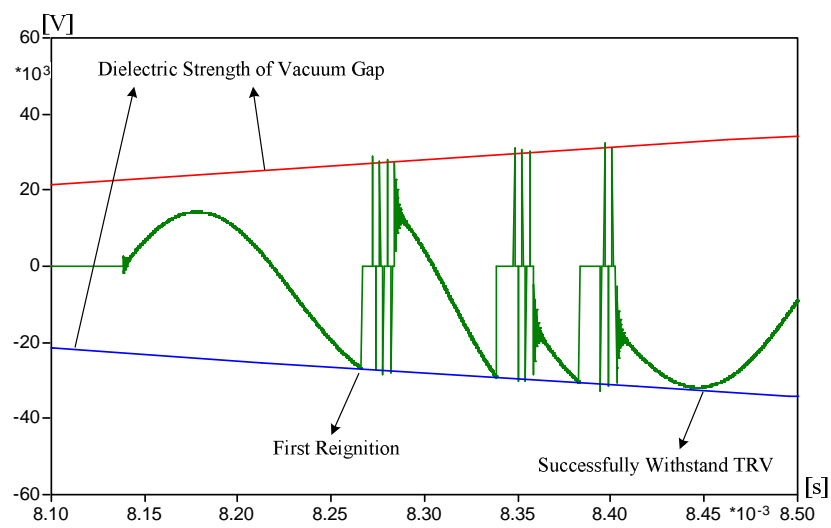

Fig. 3 Successful interruption with multiple reignitions of VCB.

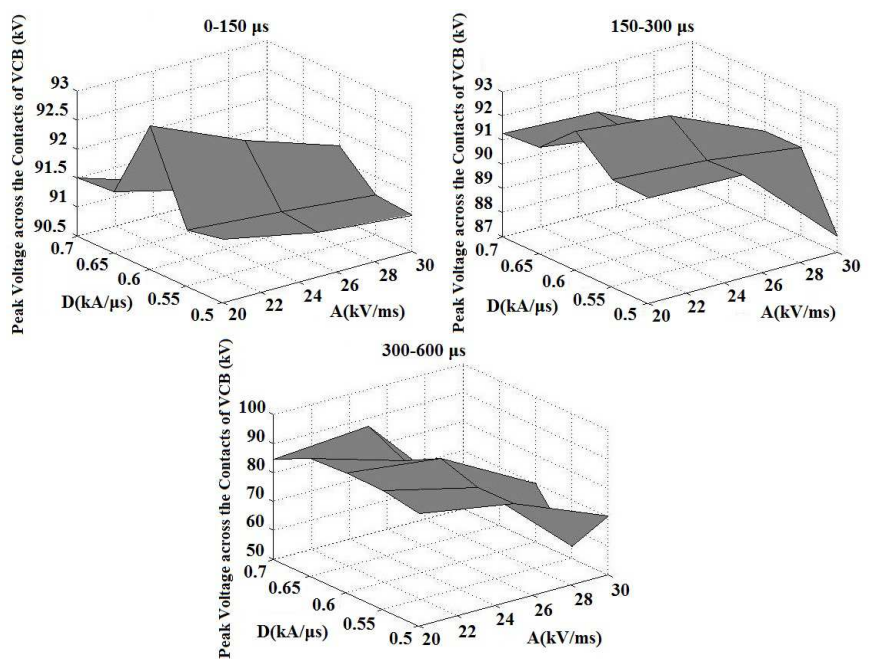

Fig. 4 Reignition behavior of VCB for three arcing time areas. 
As shown in Fig. 4, the reignition behavior is used to define the trend, which will lead to serious multiple reignitions and voltage escalations in the VCB. The worst case occurs in the combination of the middle part of the quenching capability and the minimum part of the recovery of dielectric strength; these parameters will be used for the VCB modeling.

\section{B. Cable, Generator and Busbar Modeling}

Several cable models are available in ATP-EMTP, such as PI sections, J-Marti and Semlyen. In this work, the J-Marti model is used [4]. Hard ethylene propylene rubber (HEPR) is the insulation of the single-core cables, and its relative permittivity is around 3.2 [5]. The relative permittivity of the inner and the outer ethylene vinyl acetate (EVA) sheath is around 2.8 [5]. The relative permeability of the conductor, the insulation and the surrounding material is equal to 1 . The generator is modeled as an ideal voltage source in series with its impedance [6]. The HV side of the vessel is with isolated neutral point and this is realized by applying a high zerosequence resistance in the impedance model. The effect of the saturation, the excitation, the governor system and the mechanical parts is not taken into account. Busbars are represented as cylindrical conductors and modeled by PI sections [1] since their distance is short (approximately 100 $\mathrm{cm}$ or $85 \mathrm{~cm}$ ).

\section{Induction Motor Modeling}

The induction motor is modeled according to three different switching operations. The first one is the motor switching operation under starting conditions that results because of false tripping of the protection. The second situation is the switching operation of a motor under full load condition. It may occur due to a normal process interruption. Last situation is the switching operation under light load condition. It is the most common situation when disconnecting the induction motor from the power system in the FPSO vessel.

\section{1) Induction Motor Modeling under Starting Condition}

Motor disconnection under starting conditions can cause more severe switching transient overvoltage than that under the full and the light load working conditions. During motor's start-up, the rotor does not acquire high speed to generate enough back electromotive force (EMF), which is opposite to the source voltage. The low back EMF cannot keep the TRV at a low level after contact opening. Thus, in this case the rotor is approximately locked. It is modeled according to Fig. 5.

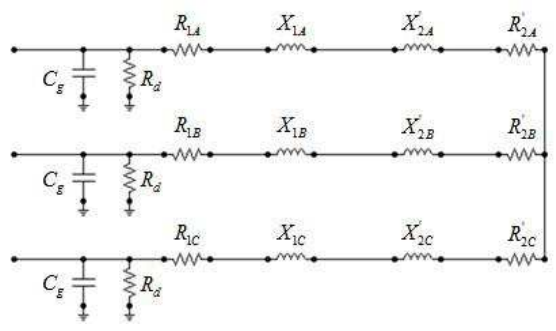

Fig. 5 T-equivalent circuit of induction motor under starting condition.

In Fig. 5, $R_{1}, X_{1}, R_{2}^{\prime}$ and $X_{2}^{\prime}$ are motor impedances and resistances for each phase, $C_{g}$ is the bushing capacitance of each phase and $R_{d}$ is the damping resistance of the motor winding for each phase. The stator magnetizing reactance $X_{m}$ is ignored, because $X_{m}$ is larger than the rotor impedance during locked rotor condition or starting condition. The values of $R_{l}$, $X_{1}, R_{2}$ ' and $X_{2}$ 'are calculated from the no load conditions and the locked rotor test reports, provided by the vendor. $C_{g}$ is the bushing capacitance also provided by the vendor. $R_{d}$ is the damping resistance that is also calculated [7].

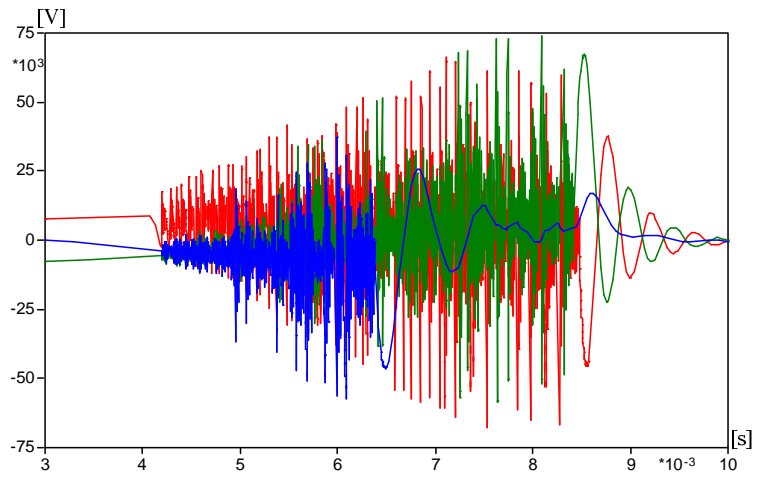

Fig. 6 Simulated three phase voltage in the terminal of T711 motor. (Red trace: phase A; Green trace: phase B; Blue trace: phase C)

As shown in Fig. 6, when the arcing time is around $350 \mu$ s, the peak value of switching overvoltage in the motor terminal is around $74.6 \mathrm{kV}$ (Phase B). For the insulation coordination, the IEC 60034-15 standard [8] suggests a BIL of $49 \mathrm{kV}$ peak value for an $11 \mathrm{kV}$ motor. This overvoltage is simulated between the motor coil terminals and the earth. Such a high overvoltage will cause large stress to the motor insulation system and decrease the motor life time. The phenomenon of virtual current chopping [9] contributes to high switching overvoltages in this situation.

\section{2) Induction Motor Modeling under Full Load Condition}

ATP's Universal Machine Type 3 (UM3) is used to model the induction motor under full load conditions. The motor parameters for this case are optimized and a modified method has been applied to extract the correct values. Details about how this is done are provided in [10]. For fast transient studies one may use simplified model with capacitances, however, in this case, this model has been used in order to provide correct currents before the switching event takes place.

TABLE II

COMPARISON OF PARAMETERS FROM DIFFERENT METHODS

\begin{tabular}{|c|c|c|c|}
\hline Item & Method [11] & $\begin{array}{c}\text { Modified } \\
\text { Method [10] }\end{array}$ & $\begin{array}{c}\text { Information of } \\
\text { Data Sheet }\end{array}$ \\
\hline$R_{1}$ & 0.045 & 0.045 & 0.045 \\
\hline$X_{1}$ & 1.39 & 2.07 & 2.32 \\
\hline$X_{m}$ & 84.51 & 83.83 & 92.5 \\
\hline$R_{2}{ }^{\prime}$ & 0.24 & 0.069 & 0.074 \\
\hline$X_{2}{ }^{\text {Trace }}$ & 1.39 & 0.708 & 0.745 \\
\hline \begin{tabular}{c} 
in Fig. 7 \\
\hline
\end{tabular} & Blue & Red & Black \\
\hline
\end{tabular}



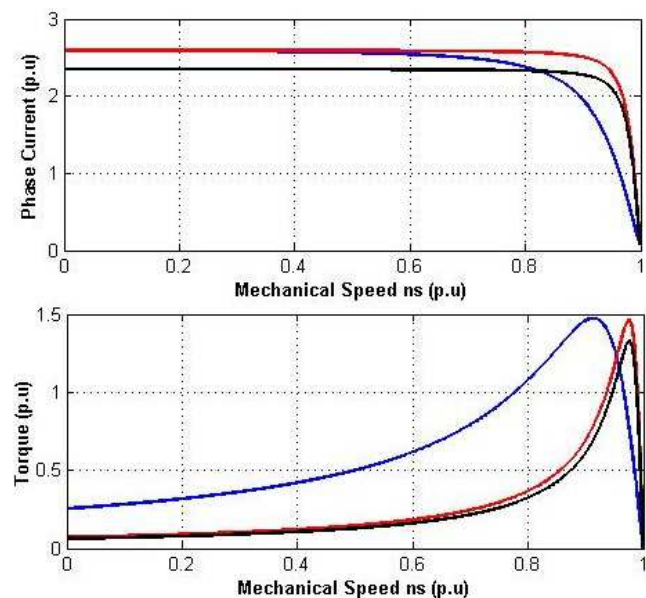

Fig. 7 Upper Trace: Phase Current-Speed characteristics; Lower Trace: Torque-Speed characteristics. (Blue trace is drawn based on column 2 of Table II; Red trace is drawn based on column 3 of Table II; Black trace is drawn based on column 4 of Table II)

Table II shows the data obtained by different methods and data provided by the vendor of the observed induction machine. From the comparison of different traces in Fig. 7, it can be seen that the data from modified method closely match the data provided by the vendor. Table III, provides the electrical and the speed characteristics under full load condition.

TABLE III

COMPARISON OF CHARACTERISTICS OF T711 MOTOR UNDER FULL LOAD CONDITION BETWEEN SIMULATION AND TEST REPORT

\begin{tabular}{|c|c|c|c|}
\hline Item & $\begin{array}{c}\text { Results of } \\
\text { Simulation }\end{array}$ & $\begin{array}{c}\text { Results of } \\
\text { Test Report }\end{array}$ & $\begin{array}{c}\text { Tolerance } \\
{[12,13]}\end{array}$ \\
\hline $\begin{array}{c}\text { Peak Value of } \\
\text { Phase Voltage (V) }\end{array}$ & 9015.1 & 9010 & $\begin{array}{c}+6 \% \text { to - } \\
10 \%\end{array}$ \\
\hline $\begin{array}{c}\text { Peak Value of } \\
\text { Phase Current (A) }\end{array}$ & 878.1 & 876.4 & - \\
\hline $\begin{array}{c}\text { Power Factor } \\
\text { under Full Load } \\
\text { Condition }\end{array}$ & 0.9 & 0.89 & $\begin{array}{c}\text { Maximum } \\
\text { Absolute } \\
\text { Value: } 0.07\end{array}$ \\
\hline $\begin{array}{c}\text { Mechanical } \\
\text { Speed (rad/s) }\end{array}$ & 187.1 & 187.07 & $\begin{array}{c}-20 \% \text { to } \\
+20 \%\end{array}$ \\
\hline Slip (\%) & 0.74 & 0.76 & $\begin{array}{c}-20 \% \text { to } \\
+20 \%\end{array}$ \\
\hline
\end{tabular}

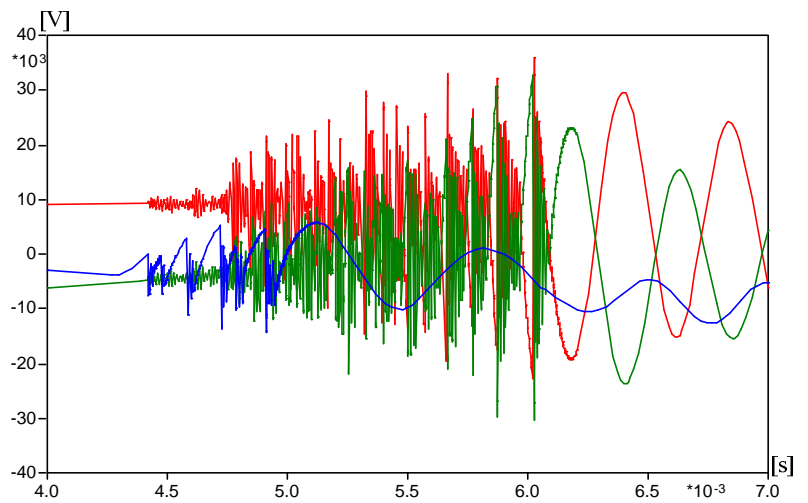

Fig. 8 Simulated three phase voltage at the terminal of T711 motor. (Red trace: phase A; Green trace: phase B; Blue trace: phase C)
When the arcing time is around $50 \mu \mathrm{s}$, the virtual current chopping is observed in the VCB; a considerable overvoltage around $35.8 \mathrm{kV}$ (Phase $\mathrm{A}$ ) occurs at the motor terminals as shown in Fig. 8. This is because the VCB does not have enough time to build up high dielectric strength due to short arcing time. As a result, multiple reignitions occur in the VCB gap and the HF current easily causes virtual current chopping.

Unlike the motor switching during start-up, the amplitude and the rate of rise of TRV is much lower for the motor under full load conditions. The overvoltage due to multiple reignitions and virtual current chopping does not reach the BIL level.

\section{3) Induction Motor Modeling under Light Load Condition}

The modeling of an induction motor under light load condition is performed by adjusting the slip and the load torque in the ATP's UM3 model. Based on the requirements of different driven machines, the phase current of light load motor is set to $20 \%$ rated phase current for a compressor and $15 \%$ rated phase current for a pump. In this case, the output power of $\mathrm{T} 711$ motor is decreased to $17.65 \%$ the rated power to approach the motor that is working under light load conditions. The parameters are the same with the motor under full load conditions besides the load torque and the slip.

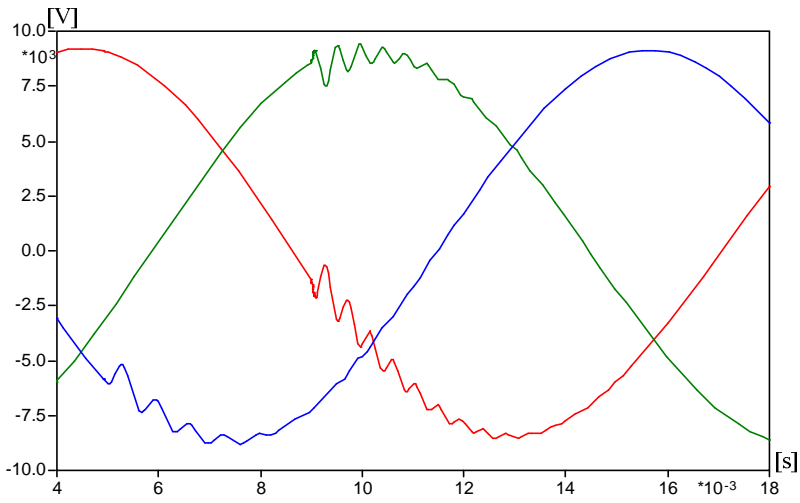

Fig. 9 Simulated three phase voltage in the terminal of T711 motor. (Red trace: phase A; Green trace: phase B; Blue trace: phase C)

The typical switching operation with around $50 \mu$ s arcing time is shown in Fig. 9. The level of switching overvoltage is much lower than that of the starting and the full load conditions. The switching overvoltage appears in phase B with the peak value around $9.4 \mathrm{kV}$. The multiple reignitions and the virtual current chopping do not occur in this case.

\section{Surge Arrester}

\section{1) Surge Arrester Modeling}

An $11.3 \mathrm{kV} \mathrm{ABB}$ metal oxide surge arrester is modeled and applied to protect the electrical equipment of the power system of the FPSO vessel. The measured volt-ampere characteristic of $11.3 \mathrm{kV}$ surge arrester is shown in Table IV. The modeling procedure of the surge arrester is fully described in [1], and the model is shown in Fig. 10. 
TABLE IV

U-I CHARACTERISTIC OF $11.3 \mathrm{kV}$ SURGE ARRESTER

\begin{tabular}{|l|l|l|l|}
\hline$U(\mathrm{kV})$ & $I(\mathrm{~A})$ & $U(\mathrm{kV})$ & $I(\mathrm{~A})$ \\
\hline 2.1 & 0.00001 & 22.5 & 500 \\
\hline 10.7 & 0.00003 & 23.8 & 1000 \\
\hline 15 & 0.0001 & 24.6 & 1500 \\
\hline 16.6 & 0.0005 & 25.9 & 3000 \\
\hline 17.1 & 0.01 & 27.2 & 5000 \\
\hline 18 & 1 & 29.1 & 10000 \\
\hline 19 & 10 & 32 & 20000 \\
\hline 21.1 & 125 & 36 & 40000 \\
\hline 21.8 & 250 & 45 & 100000 \\
\hline
\end{tabular}

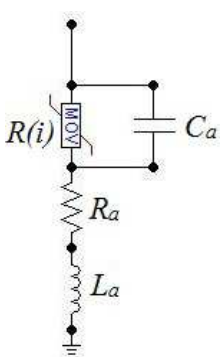

Fig. 10 Frequency-dependent surge arrester model.

$R(i)$ is a current dependent resistance, which is extracted from the non-linear volt-ampere characteristic of a metal oxide surge arrester. $C_{a}$ is a capacitance of the surge arrester block, $R_{a}$ and $L_{a}$ represent the physical characteristics of $\mathrm{Z}_{\mathrm{n}} \mathrm{O}$ grains. The parameters of the surge arrester are estimated as $R_{a}=0.06$ $\Omega, L_{a}=0.5 \mu \mathrm{H}$ and $C_{a}=0.14 \mathrm{nF}$ based on [1]. In this way, the surge arrester is modeled as a frequency dependent component, which provides correct residual voltages for a front of wave with $0.5 \mu$ s rise time, and surge impulses with shapes of $8 / 20 \mu$ s and $30 / 60 \mu$ s [1].

\section{2) Protective Effect of Surge Arrester}

As shown in Fig. 6, the switching overvoltage of T711 motor under starting condition with $350 \mu$ s arcing time is the worst case scenario.

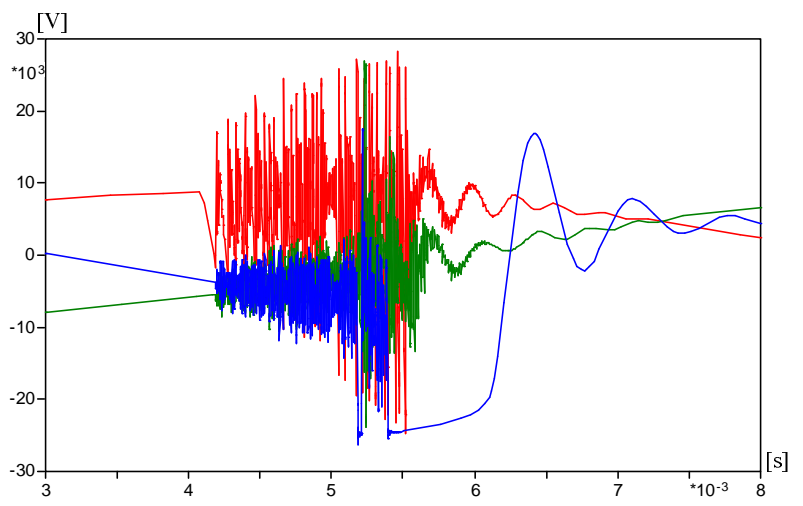

Fig. 11 Simulated three phase voltage in the terminal of T711 motor with a surge arresters connected at the terminal, the arcing time is $350 \mu \mathrm{s}$. (Red trace: phase A; Green trace: phase B; Blue trace: phase C)

Fig. 11 shows that the switching overvoltage is mitigated when applying a surge arrester at the load terminals. The phase voltage peak value is limited to approximately $28.7 \mathrm{kV}$, which is below the motor's BIL.

\section{STATISTICAL ANALYSIS OF FOUR TyPICAL LOADS}

\section{A. Results of Switching Operation of Motor under Starting Condition}

As shown in Fig. 12 through Fig. 15, four typical loads are disconnected by the VCB, and the relationship between cumulative probability and maximum phase voltage is recorded. The modeling procedure is fully described in [1].

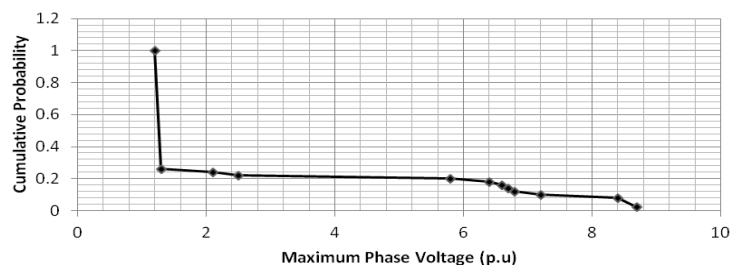

Fig. 12 Cumulative probability of maximum phase voltage in the terminal of T711 motor under starting condition without a surge arrester connected.

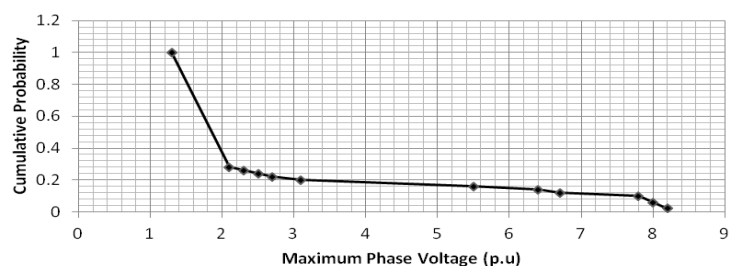

Fig. 13 Cumulative probability of maximum phase voltage in the terminal of T713 motor under starting condition without a surge arrester connected.

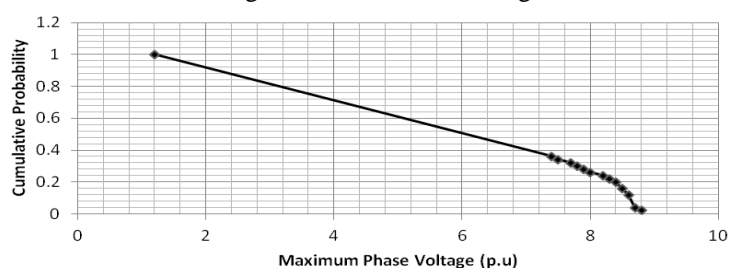

Fig. 14 Cumulative probability of maximum phase voltage in the terminal of T261 motor under starting condition without a surge arrester connected.

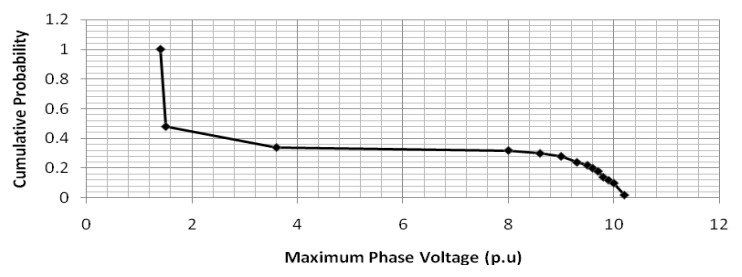

Fig. 15 Cumulative probability of maximum phase voltage in the terminal of T794 motor under starting condition without a surge arrester connected.

Fig. 12 and Fig. 13 show the influence of the cable length. The maximum phase voltage of the T713 motor is slightly lower than that of the T711 motor, because the T713 motor is connected to the VCB by a longer cable. When the cable length is increased, the lumped capacitance of cable is also increased and this results in a lower rate of rise of the TRV. As a result, the T713 motor experiences slightly lower 
overvoltage. Apart of the effect of the cable length, the above figures show that the machine with lower power produces higher switching overvoltage than that with higher power.

When the VCB generates multiple reignitions, the overvoltage may reach up to 10.4 p.u for the T794 motor, whereas the other three motors keep the overvoltage below 9 p.u. For motors with lower rated power, the motor phase current is also reduced. Hence, the probability of the occurrence of virtual current chopping rises for small machine exposed to multiple reignitions. This explanation is approved by the simulation as shown in Table V.

TABLE V

COMPARISON OF REIGNITION CHARACTERISTICS FOR T711, T261 AND T794 MOTORS

\begin{tabular}{|c|c|c|c|}
\hline $\begin{array}{c}\text { Machine } \\
\text { Type }\end{array}$ & $\begin{array}{l}\text { Times of } \\
\text { Switching } \\
\text { Operations with } \\
\text { Reignition }\end{array}$ & $\begin{array}{l}\text { Times of } \\
\text { Virtual Current } \\
\text { Chopping }\end{array}$ & $\begin{array}{l}\text { Total Times } \\
\text { of Simulation in } \\
\text { One Electrical } \\
\text { Period }\end{array}$ \\
\hline T711 & 12 & 10 & 50 \\
\hline T261 & 18 & 18 & 50 \\
\hline T794 & 17 & 16 & 50 \\
\hline
\end{tabular}

With a surge arrester connected at the motor terminals, the switching overvoltage is obviously decreased, as shown from Fig. 16 to Fig. 19. The surge arrester successfully mitigates maximum overvoltages to a relatively low level.

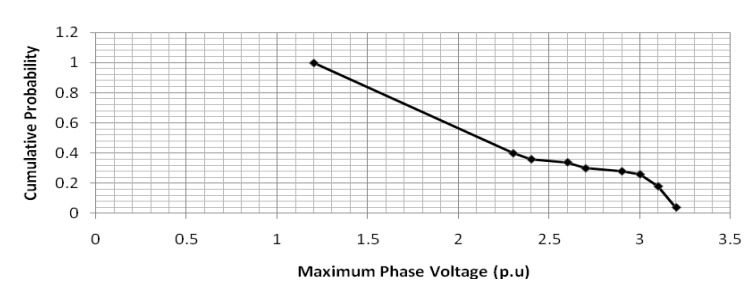

Fig. 16 Cumulative probability of maximum phase voltage in the terminal of T711 motor under starting condition with a surge arrester connected.

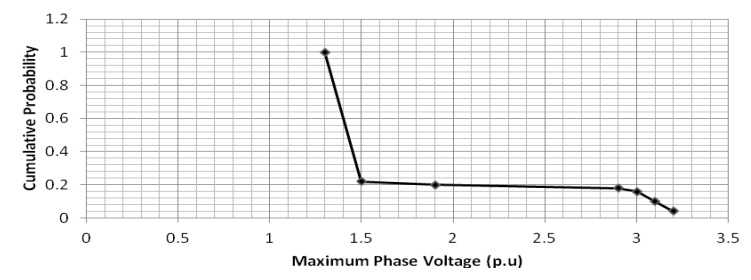

Fig. 17 Cumulative probability of maximum phase voltage in the terminal of T713 motor under starting condition with a surge arrester connected.

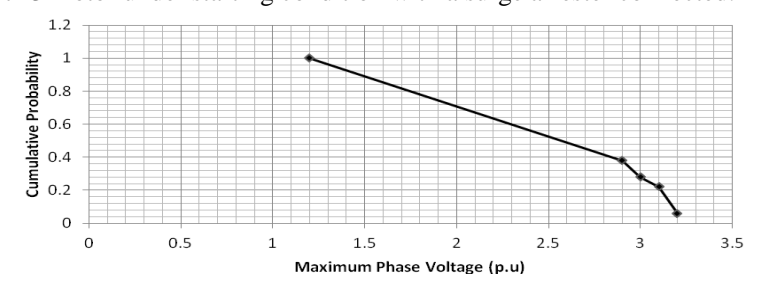

Fig. 18 Cumulative probability of maximum phase voltage in the terminal of T261 motor under starting condition with a surge arrester connected.

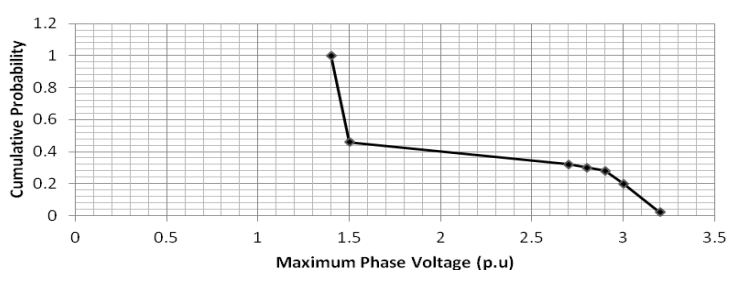

Fig. 19 Cumulative probability of maximum phase voltage in the terminal of T794 motor under starting condition with a surge arrester connected.

\section{B. Results of Switching Operation of Motor under Full Load Condition}

As shown in Fig. 20 through Fig. 23, switching overvoltages for four different motors show cumulative probabilities with phase overvoltages above 3.5 p.u. The phase overvoltages of both the T711 and the T261 motors with values between 4 p.u and 4.5 p.u occur with probability of $4 \%$, whilst those for the T713 motor experiences $2 \%$ probability for values around 3.9 p.u. On the other hand, for the low power motor T794, higher cumulative probability of approximately $10 \%$ has been calculated for overvoltages between 3.5 p.u and 4.5 p.u. Although the phase overvoltage due to multiple reignitions and virtual current chopping may reach a high value of 4.2 p.u for the T711 motor and the T794 motor, such overvoltage is still below the BIL of the $11 \mathrm{kV}$ motor. Therefore, the use of surge arresters is not really needed in this case.

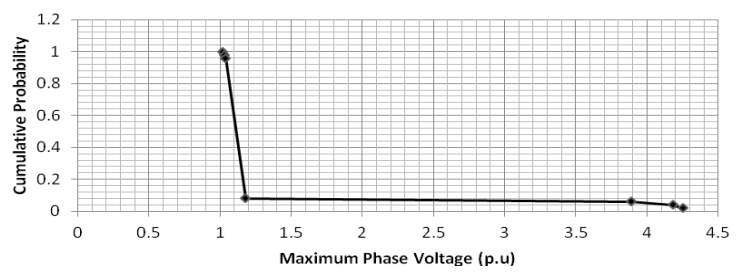

Fig. 20 Cumulative probability of maximum phase voltage in the terminal of T711 motor under full load condition without a surge arrester connected.

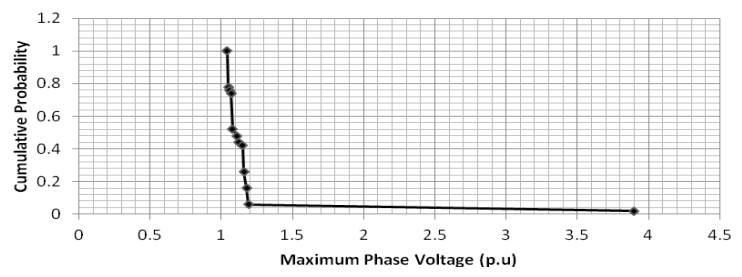

Fig. 21 Cumulative probability of maximum phase voltage in the terminal of T713 motor under full load condition without a surge arrester connected.

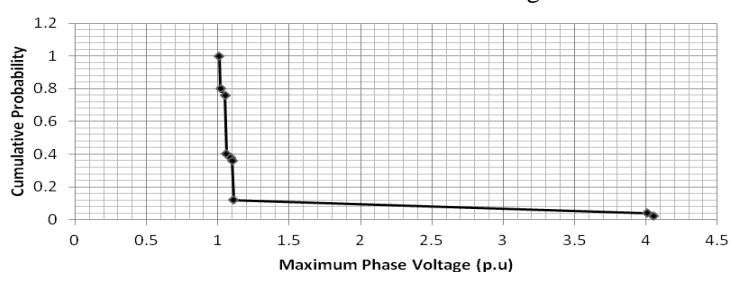

Fig. 22 Cumulative probability of maximum phase voltage in the terminal of T261 motor under full load condition without a surge arrester connected. 


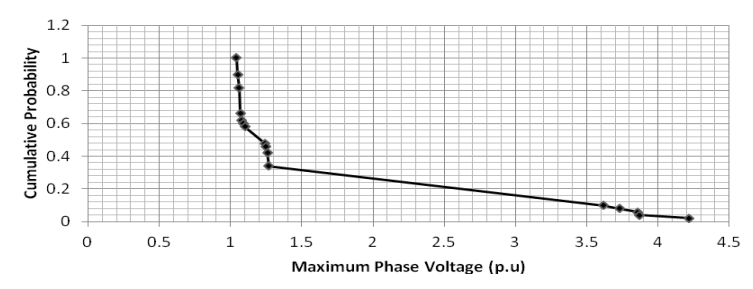

Fig. 23 Cumulative probability of maximum phase voltage in the terminal of T794 motor under full load condition without a surge arrester connected.

\section{Results of Switching Operation of Motor under Light Load Condition}

The simulations performed for four motors show that high multiple reignitions, voltage escalations and virtual current chopping are not found in this case. The main switching overvoltage is caused by the current chopping. The results for the same cases are resented in Fig. 24 through Fig. 27.

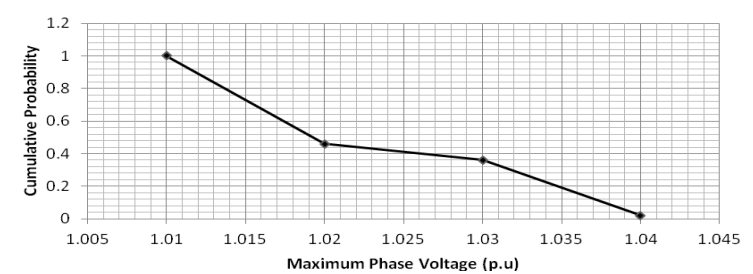

Fig. 24 Cumulative probability of maximum phase voltage in the terminal of T711 motor under light load condition without a surge arrester connected.

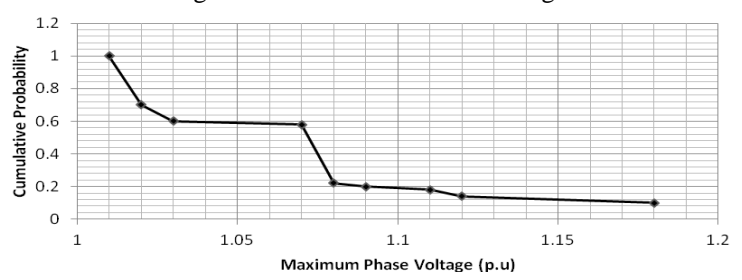

Fig. 25 Cumulative probability of maximum phase voltage in the terminal of T713 motor under light load condition without a surge arrester connected.

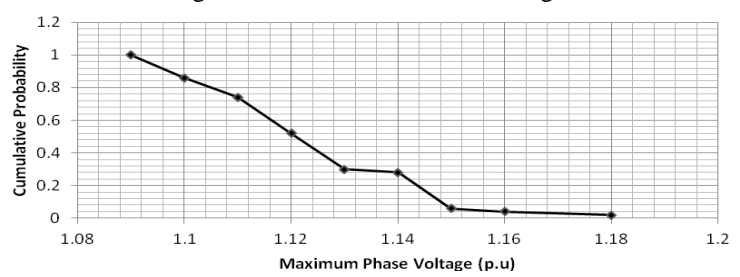

Fig. 26 Cumulative probability of maximum phase voltage in the terminal of T261 motor under light load condition without a surge arrester connected.

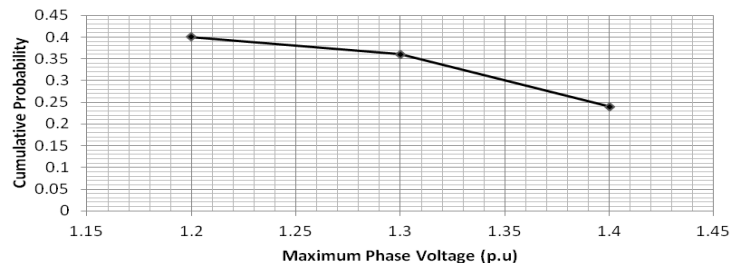

Fig. 27 Cumulative probability of maximum phase voltage in the terminal of T794 motor under light load condition without a surge arrester connected.

\section{CONCLUSION}

In this work, switching transient overvoltages in the $11 \mathrm{kV}$ power system of a FPSO vessel are analyzed. The VCB is modeled in detail and the associated network is represented by components available in ATP-EMTP. A simplified layout of the studied power system is described and used to check the switching transient overvoltages of four typical induction motors. It is found that the motor under starting conditions is exposed to the highest overvoltages, which results from the multiple reignitions and the virtual current chopping in the VCB. In this case, the overvoltage amplitude may be above the BIL of $11 \mathrm{kV}$ motor. In contrast, high switching overvoltages occur with much lower probability in case when a motor operates under full load condition, and the maximum overvoltages do not exceed the BIL of $11 \mathrm{kV}$ motor. When the motor is lightly loaded, the maximum overvoltage is low and far below the BIL of $11 \mathrm{kV}$ motor.

Based on this analysis, the installation of surge arresters is recommended for all induction motors in the $11 \mathrm{kV}$ power system of the selected FPSO vessel. The most suitable location to install surge arresters is at motor terminals. Since, the highest overvoltages occur during start-up conditions, the commissioning of the selected FPSO vessel should follow strict principles in order to avoid the possible maloperations of protection relays. These maloperations result mainly from the inrush currents during motor starting.

\section{REFERENCES}

[1] M. Popov, Switching Three-phase Transformers with a Vacuum Circuit Breaker, Analysis of Overvoltages and the Protection of Equipment, Ph.D Thesis, Delft University of Technology,2002, ISBN 90-90161244.

[2] J. Helmer and M. Lindmayer, "Mathematical Modeling of the High Frequency Behavior of Vacuum Interrupters and Comparision with Measured Transients in Power Systems," presented at the XVIIth Int. Conf. Discharges and Electrical Insulation in Vacuum, Berkeley, 1996.

[3] J. Kosmac and P. Zunko, "A Statistical Vacuum Circuit Breaker Model for Simulation of Transient Overvoltages," IEEE Trans. Power Delivery, vol. 10, no. 1, pp. 294-300, 1995.

[4] W. S. Meyer and Tsu-huei Liu, Electro-Magnetic Transient Program (EMTP) Theory Book. United States of America, 1994.

[5] M. A. Laughton, Electrical Engineer's Reference Book. Newnes, 2003.

[6] J.A.Martinez, "Parameters Determination for Power Systems Transients," presented at the IEEE PES General Meeting, Barcelona, 2007.

[7] H. T. N. Ueno, Y. Murai, M. Okada, "Monte-Carlo Simulation of Overvoltage Generation in the Inductive Current Interruption by Vacuum Interrupters," IEEE Trans. on Power Apparatus and Systems, vol. Pas-103, pp. 498 - 505.

[8] IEC Rotating Electrical Machines - Part 15, IEC Standard 6003415:2009, 2009.

[9] J. F. Perkins, "Evaluation of Switching Surge Overvoltages on Medium Voltage Power System," IEEE Trans. Power Apparatus and Systems, vol. PAS-101, p. 8, 1982.

[10] H. Xue, "Analysis of Switching Transient Overvoltages in the Power System of Floating Production Storage and Offloading Vessel," M.Sc. thesis, Dept. EEMCS, Delft University of Technology, 2012.

[11] P. C. Sen, Principles of Electric Machines and Power Electronics. Canada: John Wiley \& Sons, 1997.

[12] IEC Electrical Installations in Ships - Part 101, IEC Standard 60092101:2002, 2002.

[13] IEC Rotating Electrical Machines - Part 1, IEC Standard 60034-1:2010, 2010. 